\title{
PROCESSO DE FORMAÇÃO EDUCACIONAL E SEUS REFLEXOS NA ATIVIDADE PESQUEIRA: A REALIDADE DOS PESCADORES ARTESANAIS DO VAle Guaporé (RO)
}

\author{
TÂNIA OLINDA LIMA \\ Ana Paula da Silva Bertão \\ Eliane SiLva Leite \\ Clodoaldo de Oliveira Freitas \\ Universidade Federal de Rondônia (UNIR), Porto Velho, Rondônia, \\ Brasil
}

Resumo: A pesquisa teve o intuito de investigar os processos de formação educacional dos pescadores artesanais do Guaporé. Para isso, buscou sistematizar dados obtidos em campo, por meio de oficinas participativas e entrevistas semiestruturadas a respeito do grau de instrução dos pescadores; demandas de cursos de formação; acesso à educação e formação, dentre outros temas. O público-alvo foram os pescadores artesanais associados às Colônias de Pecadores Z-3 e Z-10, localizadas, respectivamente, nos municípios de Pimenteiras d'Oeste e São Francisco do Guaporé, Rondônia. Constataram-se diversos gargalos relacionados ao processo de formação educacional dos pescadores, pois a maioria apresenta-se com baixo grau de instrução. Isto reflete diretamente na renda das famílias, o que pode levar à evasão de jovens da atividade. Todavia, os pescadores mostraram interesse em aumentar sua formação, por meio de cursos técnicos.

Palavras-chave: Educação formal. Colônia de pescadores. Grau de instrução. Conhecimento empírico. 
COMUNIDADES TRADICIONAIS E FORMAÇÃO SOCIAL

Por meio do Decreto no 10.408 , foi instituída em 2004, no âmbito do governo federal, a Comissão Nacional de Desenvolvimento Sustentável das Comunidades Tradicionais, que sofreu alterações em 2006. O intuito era estabelecer uma política específica para avaliar, propor e harmonizar princípios e diretrizes das políticas públicas relacionadas ao desenvolvimento sustentável desses segmentos sociais nas esferas federal, estadual e municipal. A Política Nacional de Desenvolvimento Sustentável dos Povos e Comunidades Tradicionais (PNPCT) foi construída com ampla participação da sociedade civil e determinada pelo Decreto $n^{\circ} 6.040$, de fevereiro de 2007.

Dentre os objetivos específicos da PNPCT, destacamos o artigo $2^{\circ}$, inciso V:

V-Garantir e valorizar as formas tradicionais de educação e fortalecer processos dialógicos como contribuição ao desenvolvimento próprio de cada povo e comunidade, garantindo a participação e controle social tanto nos processos de formação educativos formais quanto nos não formais (BRASIL, 2007).

As expressões "populações tradicionais", "comunidades tradicionais", de acordo com Almeida (2006), são representações de seringueiros, ribeirinhos, pescadores artesanais, quebradeiras de coco babaçu, indígenas, quilombolas, ciganos, pomeranos, geraizeiros, povos de terreiro, comunidades de fundo e fechos de pasto, faxinalenses, pantaneiros, dentre outros grupos sociais tradicionais.

Filho (2015) menciona que as identidades estão respaldadas pelas ancestralidades vinculadas à identidade de pertencimento, pela memória social, voltada aos saberes e às práticas tradicionais, havendo sempre uma identidade preponderante, e sempre podendo ser acionada, somada de maneira coletiva ou individual, levando em consideração circunstâncias histórico-conjunturais, grupos de interesse e interlocutores. Portanto, ao considerarmos o trato da etnicidade, verificamos que, tanto na interação quanto na formação social, estão inclusas as dimensões inter-intrapessoais e inter-intraculturais.

Diante desse fato, a etnicidade de cada povo tem o poder de movimentar, caracterizar e cravar a importância de suas peculiaridades, o que enriquece a permanência dos saberes e conhecimentos que são enraizados pelas suas tradições historicamente.

Para Amado (2007), as ciências da educação e do conhecimento são práticas antigas, contribuindo para o processo de desenvolvimento da sociedade. Todavia, existem diversos gargalos elacunas na contemporaneidade. 
Quanto aos relatos históricos da construção do processo educativo, diversas formas destes relatos são necessárias para a realização do conhecimento.

No entanto, não são unicamente responsáveis pelas decorrentes mudanças sociais, pois características orientadas por indivíduos ou estruturas socioeconômicas dominantes contribuem para esses problemas, impedindo a própria transformação e a da sociedade (SCHRAM; CARVALHO, 2007).

O processo educativo é o comportamento marcante no cotidiano das nossas vidas e é o mais habitual dos processos que orienta o nosso agir (ITURRA, 1994). Conduta esta que influencia o ser humano que está em transformação, fruto das vivências e realidades diárias de forma inconsciente. Como instrumento, este sujeito social é uma representação dos modelos sociais fragmentados pelos exemplos de estrutura familiar da atualidade.

Iturra (1994, p. 8) relata ainda que:

O processo educativo é uma consequência da memória pessoal como e o porquê da sua experiência histórica, tenta retirar os mais novos da inconsciência do seu saber daquilo que é percebido sem que seja explícito; e procurar inserir os mais novos nas taxonomias culturais.

Josso (2007) constata a relevância das pesquisas efetuadas com as histórias de vida e evidencia a exigência metodológica de pensar as facetas existenciais da identidade, por meio de uma abordagem multirreferencial que integra os diferentes registros do pensar humano, como as crenças científicas e religiosas, esotéricas e outras. Desta forma, destacam-se as diferentes dimensões de nosso ser no mundo.

Existem poucos estudos na área educacional no âmbito da família e sua influência no processo de transformação do indivíduo (GARCIA, 2007). Quando procuramos pesquisas relacionadas às comunidades pesqueiras, verificamos que a frequência é menor ainda. Os processos educacionais são caracterizados por reflexos na qualidade de vida pessoal e familiar dos pescadores artesanais. Esta é uma das complexidades da educação, pois esta é considerada uma teia de relações na qual se estabelece a importância dos pescadores(as) em seu modo de vida e do convívio em suas comunidades pesqueiras.

Esta pesquisa busca investigar os processos educacionais dos pescadores artesanais das colônias de pescadores do município de Pimenteiras do Oeste e de São Francisco do Guaporé, localizados na Região do Vale do Guaporé, Rondônia, Brasil. 


\section{POLÍTICAS PÚBLICAS E ACESSO À FORMAÇÃO EDUCACIONAL}

Pacheco (2012) destaca que os programas de atendimento às comunidades pesqueiras deveriam contar com ações continuadas de políticas públicas integradoras voltadas aos interesses dos pescadores e pescadoras, como saída à situação atual.

Alguns ministérios, segundo Lima e Callou (2015) a saber: Ministério da Pesca e Aquicultura (MPA), Ministério do Desenvolvimento Agrário (MDA), Ministério do Desenvolvimento Social (MDS), Ministério da Integração Nacional (MIN), Ministério da Saúde (MS), Ministério do Trabalho e Emprego (MTE), Ministério da Previdência Social (MPS) e Ministério da Educação (MEC), uns até extintos, relacionavam ou relacionam suas políticas à pesca artesanal. Quanto ao MEC, podemos destacar algumas políticas públicas para a promoção da inclusão social dos pescadores e pescadoras artesanais, tal como o Projeto Político Pedagógico, do Programa Pescando Letras, cujo objetivo era a ampliação do direito de acesso à alfabetização promovida pelo MEC por meio do Programa Brasil Alfabetizado.

Esse programa buscava, por meio da sua proposta pedagógica, problematizar as condições de vida dos pescadores artesanais, com especial atenção para os saberes empíricos no processo geracional. Portanto, não se limitava apenas à alfabetização dos interessados, servindo como elemento agregador. Nessa perspectiva, a alfabetização é considerada apenas o começo de um processo mais amplo do aprendizado da leitura e da escrita, de continuidade da escolarização, de formação permanente ligada ao trabalho.

Outras políticas públicas associadas à qualificação profissional de pescadores e pescadoras podem ser vistas por meio dos cursos de Formação Inicial e Continuada (FIC), do programa de acesso ao ensino técnico, contribuindo para o aprimoramento profissional, o que garante a participação de atores sociais com pouca experiência no setor pesqueiro. O curso busca capacitar nas áreas de redução de perdas na qualidade do pescado, aperfeiçoamento nas técnicas de manipulação, gestão de custo, beneficiamento do pescador, manejo de produção e noções em segurança da navegação (MPA, 2015).

Todavia, mesmo com todas essas políticas públicas de acesso à educação básica e profissional, pode-se perceber, por meio do trabalho de Alencar e Maia (2011), que no Brasil ainda existem 56.218 pescadores analfabetos, correspondendo a $8,1 \%$ do total de pescadores registrados. A pesquisa aponta que $75,5 \%$ têm apenas o ensino fundamental incompleto. Somando-se aos 5,7\% com ensino fundamental completo, o número 
atinge 563.284 pessoas. Apenas 69.763 cursaram o ensino médio, os que não completaram esse nível de escolaridade são 30.459 (4,4\%), enquanto $39.214(6,6 \%)$ têm ensino médio completo. Restam, assim, apenas 0,65\% dos pescadores registrados que tiveram acesso ao ensino superior (incompleto ou completo).

Ao analisar a distribuição dos pescadores por escolaridade com relação às cinco grandes regiões brasileiras, é possível observar o mesmo padrão apresentado nacionalmente. A maioria dos registros está concentrada na categoria“"Ensino Fundamental Incompleto", com valores variando entre 71,5\% para a Região Sudeste e 82,8\% para a Região Norte (ALENCAR; MAIA, 2011).

Dessa maneira, podemos verificar o gargalo atual da pesca artesanal no que tange o acesso às políticas públicas, pois a existência dessas políticas públicas não é o suficiente para que elas sejam acessíveis, principalmente em razão da distância destas comunidades dos polos de ensino. Assim, os pescadores procuram desenvolver suas atividades e aprender com os ensinamentos passados de pais para filhos.

Tradicionalmente, a educação se distingue em duas categorias, sendo a primeira a educação escolar e a segunda a educação familiar, também conhecidas como educação formal e informal (GROPPO; GOUSSAIN, 2016). Portanto, devemos levar em consideração a formação endógena e empírica do pescador artesanal, assim como valorizar e respeitar sua cultura e seu modo de interação com o meio ao seu redor.

Groppo e Goussain (2016, p. 267) mencionam que:

[...] toda gama de aprendizagens que realizamos (tanto no papel de ensinantes como de aprendizes) que acontece sem que nos demos conta. Acontece ao longo da vida, constitui um processo permanente e contínuo e não previamente organizado (Groppo; Goussain, 2016, p. 267).

\section{DESCRIÇÃO DOS INSTRUMENTOS DA PESQUISA}

A abordagem metodológica utilizada para a pesquisa determinou uma postura reflexiva, estabelecendo objetivos, metas e pleiteando intervenções de pesquisa através de ação de extensão.

No decorrer do trabalho, houve a aplicação de entrevistas semiestruturadas, sendo entrevistados $75 \%$ dos associados de cada colônia, na busca de pesquisar o processo de formação dos pescadores do município de São Francisco Colônia Z-10 (Figura 1a) e do município de Pimenteiras Colônia Z-3 (Figura 1b), ambos localizados na região do Vale do Guaporé, Rondônia, Brasil. 
Figura 1- (a) Localização dos municípios São Francisco do Guaporé de; (b) e de Pimenteiras em Rondônia.
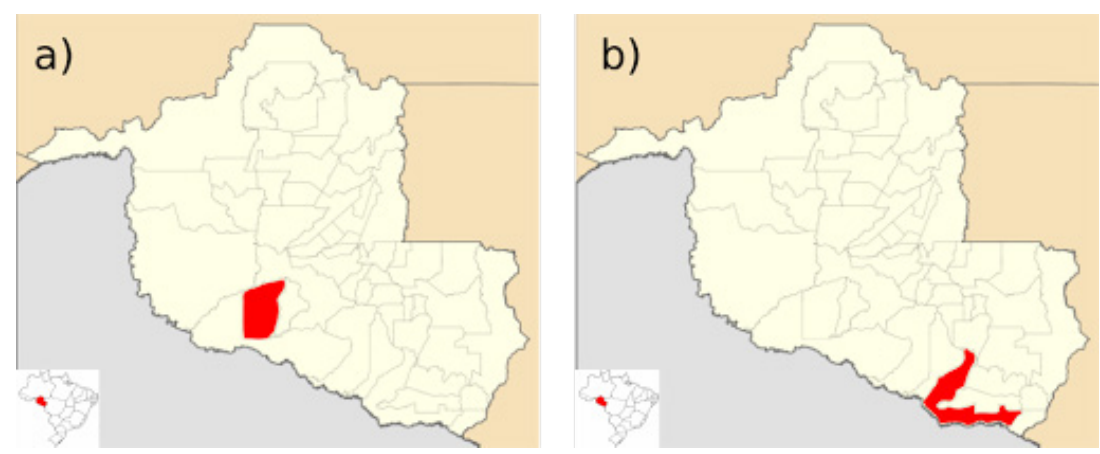

Fonte: Wikipédia (adaptado pelos autores, 2017).

As entrevistas foram associadas a perguntas diretas em forma de questionário, com o objetivo de recolher informações acerca do grau de instrução dos pescadores, demandas por cursos de formação, acesso à educação, dentre outros temas que contribuam para alcançar o objetivo da pesquisa.

A Colônia de Pescadores Artesanais Z-10 conta aproximadamente com 90 associados. Os pescadores cadastrados são dos mais diversos estratos culturais, entre afrodescendentes, seringueiros, indígenas, ribeirinhos, bolivianos e outros, que vivem da atividade pesqueira e enriquecem o Vale do Guaporé com seus costumes e saberes milenares na Figura 2a, o presidente da Colônia, com um tucunaré (Cicla sp.), apresenta a ictiofauna local. Quanto à Colônia de Pescadores Artesanais Z-3 de Pimenteiras do Oeste, fundada em 20 de maio de 1985, segundo dados obtidos com a diretoria da colônia, atualmente existem 83 associados ativos. Estão apresentados na Figura 2b o trabalho da atividade pesqueira e algumas das embarcações utilizadas. 
Figura2 - (a) Presidente da Colônia Z-10 mostrando o fruto da pescaria do dia; (b) Associado da Colônia Z-3 chegando da pescaria.
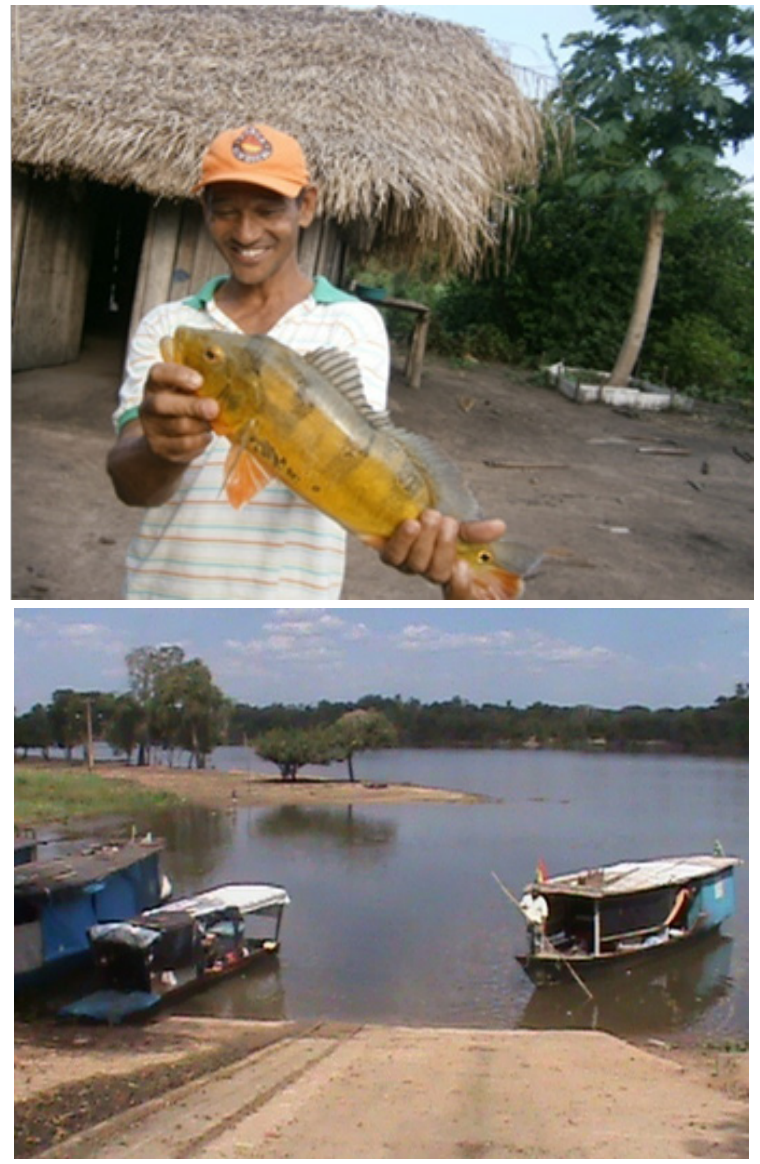

Fonte: Os autores, 2012.

\section{RESUlTADOS E DISCUSSÕES}

Como pode ser observado no Gráfico 1, tanto os pescadores da Colônia Z-10, localizada no município de São Francisco, quanto da Colônia Z-3, do município de Pimenteiras, se encontram com idade elevada, respectivamente $34 \%$ entre 26 e 45 anos e $48 \%$ de 45 a 60 anos, ou seja, não está havendo um recrutamento na atividade pesqueira nas regiões em estudo (Figura 3). Cardoso (1997, p. 3) diz que “há uma nova realidade sendo 
vivida por muitas comunidades pesqueiras, quebrando uma antiga tradição de filhos que crescem e tornam-se exclusivamente pescadores como os pais".

Figura 3 - Faixa etária dos pescadores entrevistados.

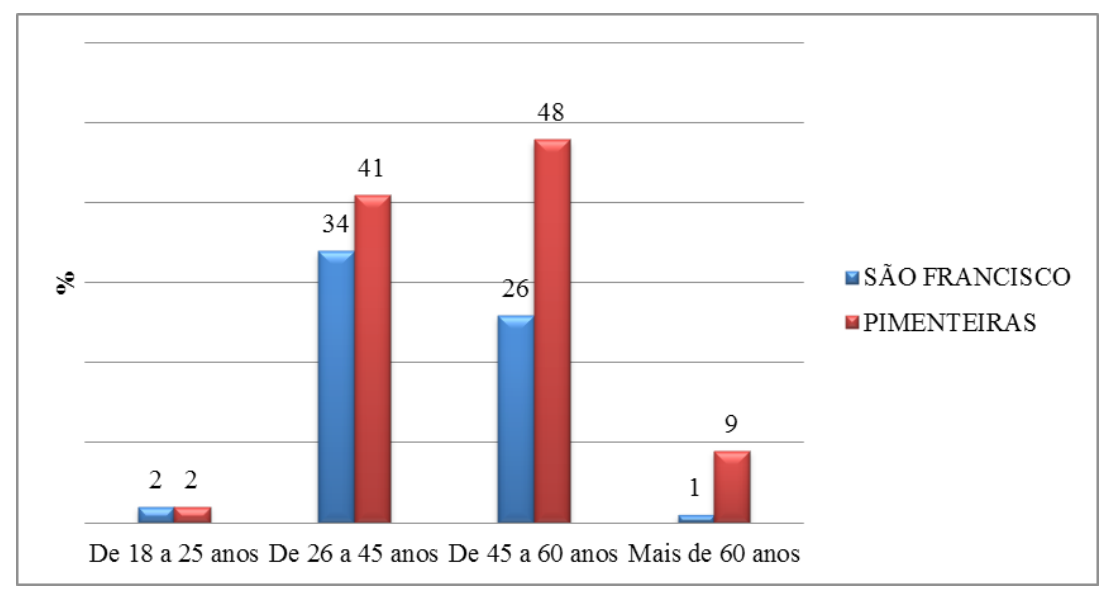

Fonte: Elaborado pelos autores, 2012.

O desinteresse dos jovens pela atividade pesqueira é uma característica nacional e está associado principalmente à desvalorização da atividade, em contrapartida a uma crescente oferta de novos postos de trabalho, sobretudo por meio do turismo, que absorve grande contingente de jovens ainda sem qualificação profissional (PEDROSA, 2007).

Quanto à renda mensal dos pescadores artesanais, destacamos que $60 \%$ dos entrevistados da Colônia Z-10 recebem até 1 salário mínimo; $61 \%$ dos pescadores da Colônia Z-3 relataram receber entre 1 e 3 salários mínimos. Todavia, esse valor é devido a uma agregação na renda por parte de políticas públicas do governo federal, como Bolsa Família, benefícios da Previdência Social (INSS) e Seguro Defeso (Figura 4). 
Figura 4 - Renda mensal dos pescadores.

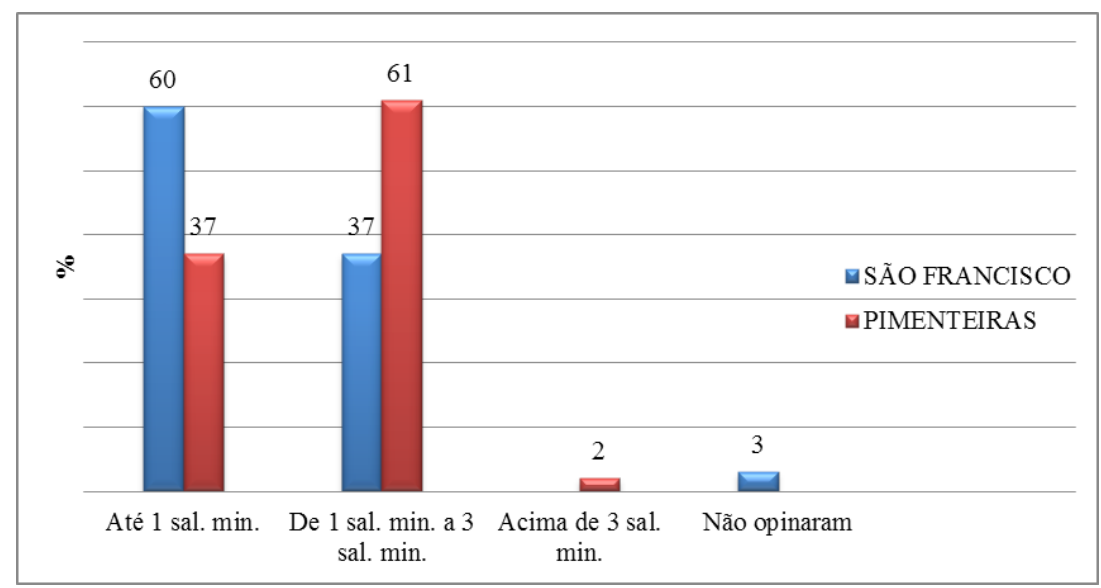

Fonte: Elaborado pelos autores, 2012.

Borges et al. (2016) relatam a importância do auxílio defeso para as famílias pescadoras, observando que a maioria delas tem acesso a esse benefício, o que permite o seu sustento em épocas de proibição da pescaria, ajudando principalmente como fonte exclusiva de renda. Esse benefício é pago ao pescador artesanal que fica proibido de exercer a atividade pesqueira durante o período de reprodução de algumas espécies.

A qualidade de vida e as possibilidades de emprego, juntamente com a qualificação profissional de uma pessoa, sofrem influência direta em relação ao grau de escolaridade (GOMES et al., 2009). Percebeu-se que as duas colônias (Z-10 e Z-3) apresentam um grande número de pescadores com nível de escolaridade baixa, apenas o $1^{\circ}$ grau incompleto, respectivamente $54 \%$ e $38 \%$ (Figura 5). Tal situação gera certas dificuldades em relação ao cotidiano da comercialização, da negociação com clientes e de vendas futuras, consequentemente refletindo na renda de suas famílias. 
Figura 5 - Grau de instrução dos pescadores.

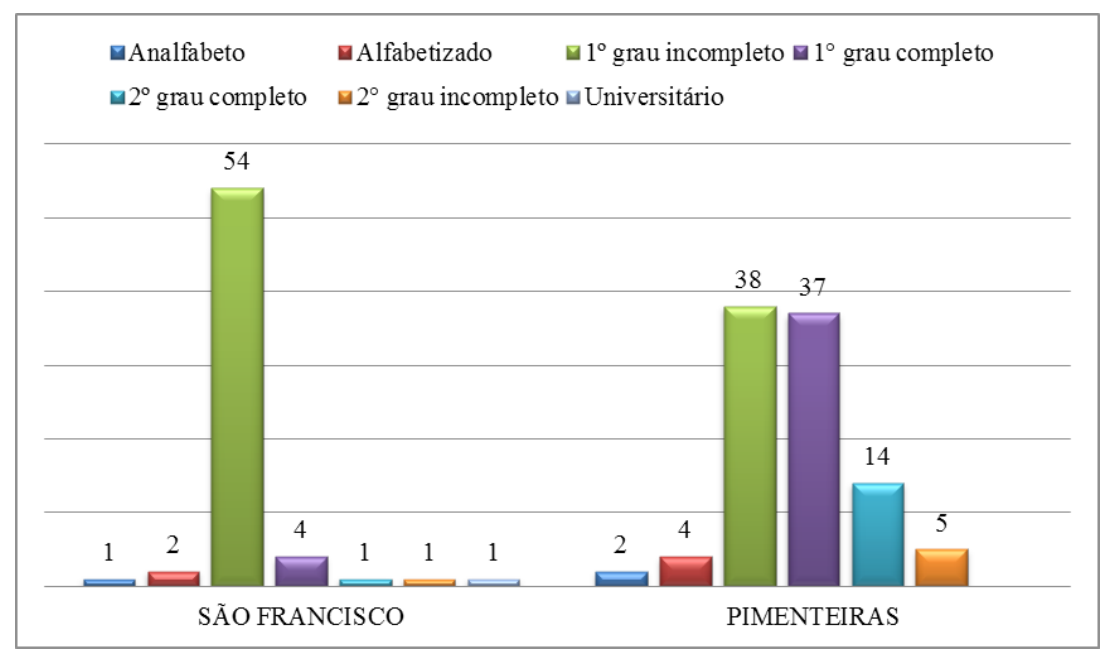

Fonte: Elaborado pelos autores, 2012.

O grande número de pescadores com baixo nível de escolaridade deve-se, principalmente, à falta de estímulo, visto que os modelos educacionais seguidos pelas escolas, em sua maioria, não levam em consideração a sua cultura, seu tempo-espaço, seus saberes, sua vida (MORAES; LOPES, 2008). Outro fator relevante que faz com que eles não permaneçam na escola no período escolar é em função do tempo, pois exercem a atividade pesqueira durante o dia e à noite. Nos horários vagos, consertam os apetrechos de pesca e ainda atuam nas atividades relacionadas à limpeza, ao preparo e à comercialização do pescado junto à família.

Em geral, a maioria dos entrevistados tem dependentes em sua família. A Colônia de Pimenteiras apresentou maior número de dependentes em relação à de São Francisco, como demostra a Figura 6. 13\% das famílias têm acima de cinco dependentes, todavia, a quantidade varia entre duas e três pessoas por moradia, respectivamente, $27 \%$ e $16 \%$. 
Figura 6 - Quantidade de dependentes por família.

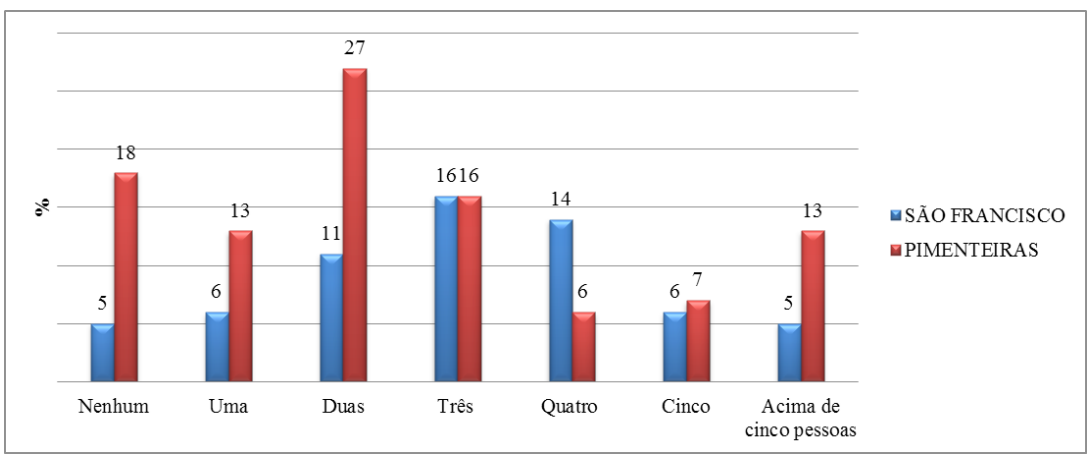

Fonte: Elaborado pelos autores, 2012.

Essa realidade pode ser notada também nas pesquisas de Branco et al. (2007) e Alves da Silva et al. (2008). Este último trabalho mostrou que o número médio de dependentes dos pescadores entrevistados foi de $4 \pm 2$, composto, na maioria das vezes, pela esposa e pelos filhos. No entanto, em $42,9 \%$ das residências, o número de pessoas foi um pouco maior, com média de $5 \pm 2$ pessoas por residência. Entretanto, também foram relatados até nove dependentes, devido à ocorrência de mais de uma família compartilhando a moradia. Tal situação provavelmente ocorre porque os filhos casados não tinham autonomia para viver em casas separadas.

Quanto à mão de obra ocupada nas embarcações para as pescarias, $65 \%$ dos entrevistados de Pimenteiras e $41 \%$ de São Francisco são familiares. Essa situação pode ser explicada pelo gráfico anterior, no qual foi mostrado o grande número de dependentes, sendo que estes se envolvem direta ou indiretamente na atividade (Figura 7). 
Figura 7 - Mão de obra ocupada durante as pescarias pelos entrevistados.

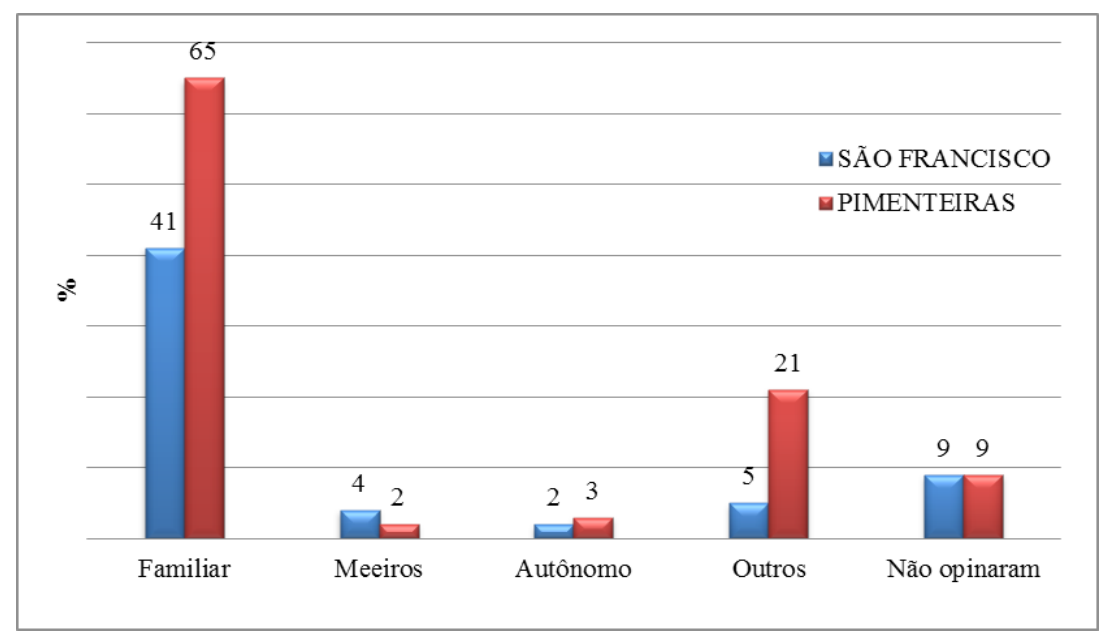

Fonte: Elaborado pelos autores, 2012.

Percebe-se a importância das interações entre pais e filhos, ou mãe e filhas, para a transmissão e o ensino da cultura pesqueira, buscando sempre a permanência e a resistência locais, bem como a definição de papéis entre homens e mulheres, em que todos os membros do contexto familiar participam e procuram estar envolvidos ativamente na realização das atividades familiares (GARCIA, 2007).

Essa interação é afirmada na Figura 8, pois tanto os pescadores de São Francisco quanto os de Pimenteiras 35\% e 49\% respectivamente mencionaram ter aprendido a pescar com seus pais. 
Figura 8 - Conhecimento adquirido na atividade pelos pescadores.

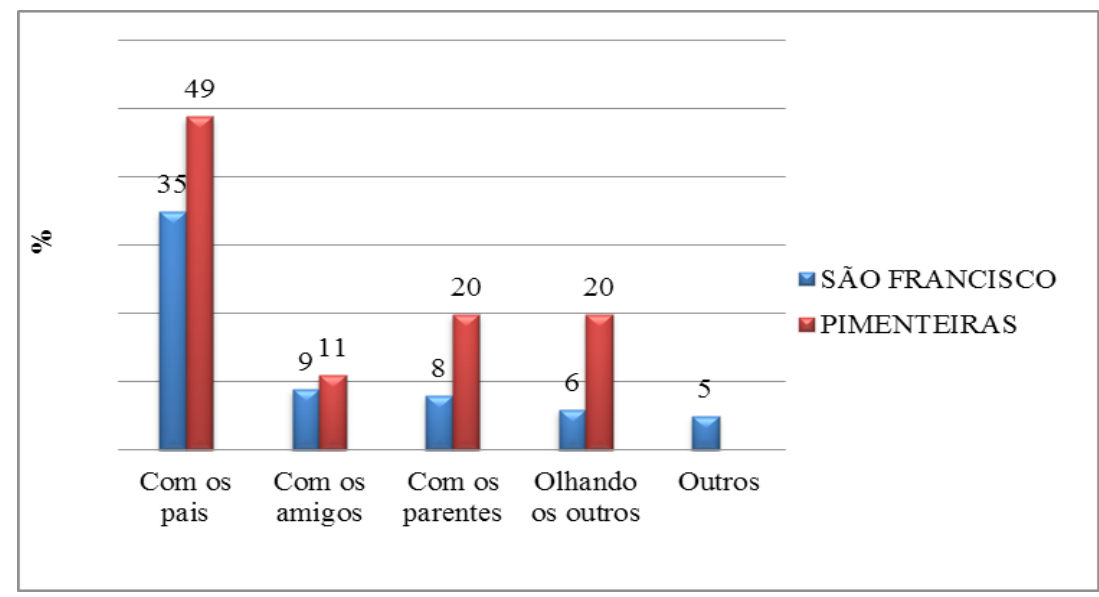

Fonte: Elaborado pelos autores, 2012.

A família, como uma imprescindível base de vários eixos da sociedade, também tem uma importante atuação no contexto de desenvolvimento humano, o que propicia interações significativas entre as pessoas e destas com os diversos contextos (RODRIGO; PALACIOS, 2014). "Essas relações implicam processos de criação cultural e tecnológica e processos históricos e sociais de transformação do meio natural e construído" (REIGOTA, 1994, p. 14).

A pesquisa apontou que existe, por parte dos pescadores, uma grande demanda quanto ao processo de formação, como pode ser observado tanto nas falas dos mais antigos quanto dos mais jovens. Os principais cursos demandados foram: navegação, mecânica e manutenção de motores, primeiros socorros, beneficiamento de pescados, informática, entre outros (Figura 9). 
Figura 9 - Demanda de formação levantada pelos pescadores.

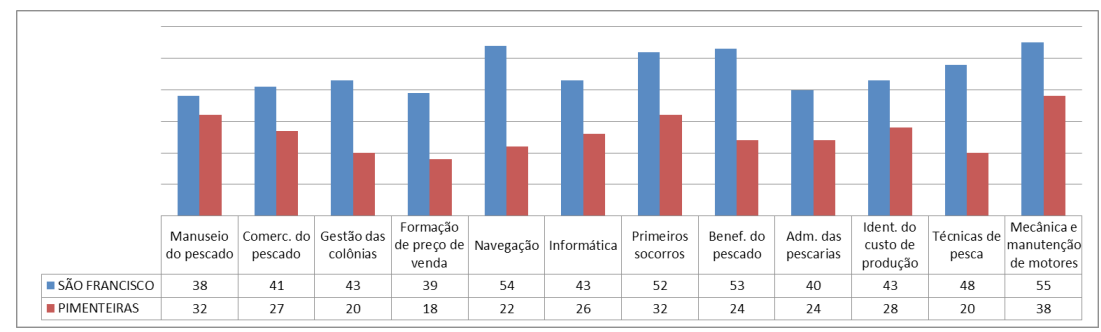

Fonte: Elaborado pelos autores, 2012.

As famílias de pescadores artesanais são grupos que mantêm uma cultura específica agregada aos saberes geracionais e identitários. Em geral, essas populações detêm e constroem conhecimentos sobre a natureza, sua dinâmica e os movimentos dos ecossistemas que atravessam várias gerações através de histórias, rodas de conversas e reuniões familiares (PAIOLA; TOMANIK, 2002). Portanto, verifica-se que há uma formação empírica por parte dos pescadores, pois o convívio rotineiro na atividade da pesca exige do pescador conhecimentos quanto a local de pesca, interferência climática, fases lunáticas, astronomia voltada para a pesca, observação e manejo pesqueiro, hábitat da espécie-alvo, área de reprodução e desovas, melhores apetrechos para a captura de determinada espécie, entre outros.

A Figura 10 aponta que $45 \%$ dos filhos dos pescadores da Colônia Z-3 de Pimenteiras e $24 \%$ de São Francisco não estão estudando ou realizando algum tipo de formação profissional.

Figura 10 - Quantidade de filhos dos pescadores que estão estudando.

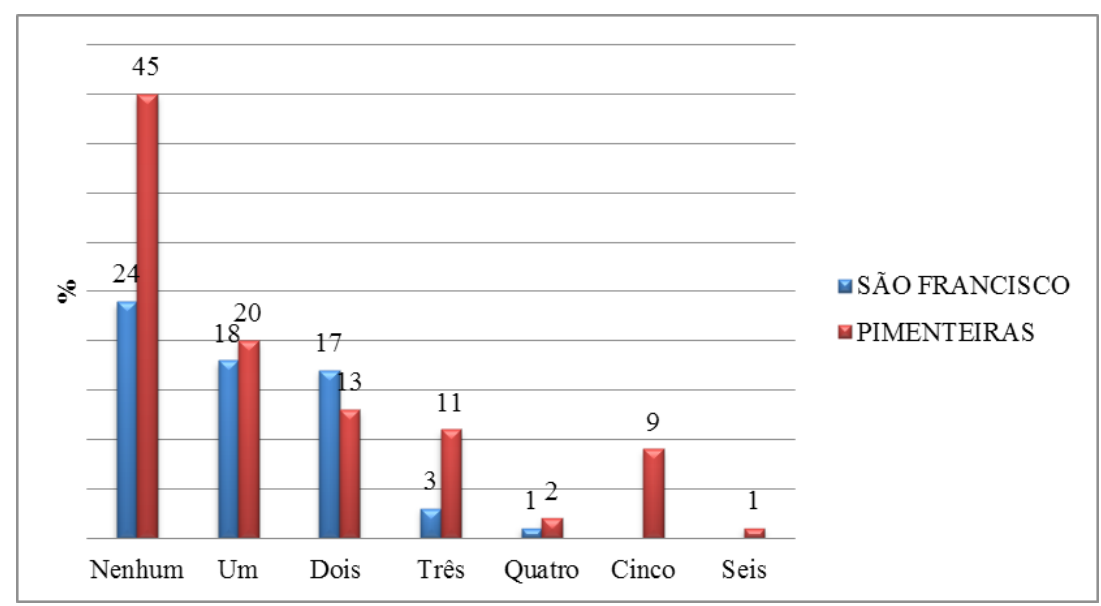

Fonte: Elaborado pelos autores, 2012. 
Lima e Callou (2015), ao mapearem as políticas públicas para o setor pesqueiro, constataram uma ampla demanda de incentivos para a produção, comercialização, assistência técnica, saúde, seguridade social, educação, meio ambiente, etc. Muitas destas políticas têm caráter inclusivo de promoção da qualidade de vida, o que faz criar novas oportunidades de trabalho e geração de renda. O extinto Ministério da Pesca e Aquicultura (MPA) promovia ao setor pesqueiro ações voltadas a projetos de formação técnica profissional de pescadores e de inclusão digital. Também havia investimentos direcionados à qualificação de jovens pescadoras e pescadores, no âmbito da inclusão digital, ao programa de alfabetização de jovens e adultos e a cursos diversos de capacitação técnica, formando parcerias com o Ministério do Trabalho e Emprego (MTE) e o Ministério da Educação (MEC).

No entanto, os pescadores destacaram a dificuldade de acesso a essas políticas públicas de educação, apontando que as comunidades, muitas vezes, não dispõem de conhecimento sobre como ter acesso a elas.

Tal fato é corroborado por Freitas (2015, p. 102), que, ao analisar o contexto da pesca artesanal no Vale do Guaporé, identificou que:

Os pescadores sofrem com a ausência de políticas públicas de forma conclusiva. Apontam-se as demandas mais urgentes de serem levantadas, que são os principais fatores que acabam interferindo na gestão como um todo da entidade. Sugerem aos poderes públicos as seguintes ações:- Realização de cursos de alfabetização no período de defeso para que os pescadores e familiares possam retirar a carteira de pilotos de barco; aprender informática; conhecer as leis ambientais; aprender a trabalhar com o beneficiamentodo pescado, processamento do peixe desde o momento da captura até acomercialização agregando valor e transformando-os em farinha, ração, bolinho de peixe, entre outros [...].

\section{CONSIDERAÇÕES FINAIS}

A pesquisa aponta diversos gargalos quanto ao acesso dos pescadores artesanais e seus familiares à formação educacional, além da dificuldade de acesso às políticas públicas, gerando, portanto, diversas demandas voltadas à capacitação dos pescadores, com especial atenção aos jovens pescadores, pois apresentam baixo grau de instrução.

Portanto, é necessária a realização de políticas públicas de formação continuada que contribuiriam para o desenvolvimento sustentável da atividade, assim como das famílias, como, por exemplo, oficinas de aprendizado, programas de alfabetização, cursos técnicos, entre outros. 
Dessa forma, seria possível contribuir para a elevação do nível técnico e de alfabetização dos pescadores artesanais, refletindo na continuidade do setor e na estruturação da cadeia de produção gerada pela pesca e reduzindo o ciclo de evasão de jovens para outras localidades, pois se garantiriam melhores oportunidades de trabalho e melhoria de vida para as famílias.

É necessário um estudo mais aprofundado sobre a implementação de escolas de capacitação e cursos técnicos vinculados às políticas públicas do governo (federal, estadual e municipal), contribuindo para o aumento da renda dos pescadores e a ascensão do grau de escolaridade dos entrevistados, com a oferta de horários mais apropriados para que estes possam ter acesso a tais capacitações sem prejudicar a atividade pesqueira.

Para tanto, verifica-se ainda a necessidade de os membros diretores das colônias firmarem parcerias com instituições ofertantes de cursos, garantindo o acesso à formação dos associados e seus familiares, por meio de políticas públicas de educação, e levando-se em consideração o contexto sociopolítico dessa população, além do desafio de fortalecer a sua participação na construção de espaços democráticos.

Artigo recebido em: 25/03/2017

Aprovado para publicação em: 16/05/2017

PROCESS OF EDUCATIONAL BACKGROUND AND ITS EFFECT ON THE FISHING ACTIVITY:THE REALITY OF THE ARTISANAL FISHERMEN IN VALE GUAPORÉ (RO)

ABSTRACT: The research had the goal to investigate the processes of the educational background of the artisanal fishermen of the Guaporé River. For so, data systematization was done in the field, by participative workshops and semi-structured interviews regarding the fishermen's background; to identify the demand of training courses; their access to education and development; among other topics. The target group was the artisanal fishermen associated with the fisherman's villages Z-3 and Z-10, located, respectively, in the cities of Pimenteiras d'Oeste and São Francisco do Guaporé, Rondônia. Several bottlenecks related to educational formation were found, whereas the majority shows a low level of education, this reflects directly on the income of the families, which could lead to school evasion of the young people working in this activity. However, the fishermen showed interest in increasing their levels of education, with technical courses.

KEYwords: Formal education. Fishermen's village. Educational background. Empirical knowledge. 
PROCESO DE FORMACIÓN EDUCACIONAL Y SUS REFLEJOS EN LA ACTIVIDAD PESQUERA: LA REALIDAD DE LOS PESCADORES ARTESANALES DEL VALLE GUAPORÉ (RO)

RESUMEN: La investigacióntuvolaintenciónde investigar losprocesos de formación educacional de los pescadores artesanales de Guaporé. Com éstefin, buscó sistematizar datos obtidos en campo, por medio de oficinas participativas y entrevistas semiestructuradas acerca delnivel de instrucción de los pescadores; demanda de recursos de formación; acceso a laeducación y formación; entre otros temas. El público objetivo fueronlos pescadores artesanalesasociados a lasColonias de Pescadores Z-3 y Z-10,localizados emPimenteiras d'OesteySão Francisco do Guaporé,Rondônia. Fueron encontrados vários obstáculos relacionados al proceso de formación educacional de los pescadores, pueslamayoría se presentan com bajo nivel de instrucción, estoreflejedirectamenteenelingreso familiar, podiendollevar a fuga de jovenes de laactividad. Sin embargo los pescadores mostraroninterésen aumentar suformación, por medio de cursos técnicos.

Palabras Clave: Educación formal.Colonia de pescadores. El Grado(nivel) de instrucción. Conocimiento empírico.

\section{REFERÊNCIAS}

ALENCAR, C. A. G.; MAIA, L. P. Perfil socioeconômico dos pescadores brasileiros. Revista Arquivos de Ciências do Mar, Fortaleza, v. 44, n. 3, p. 12-19, 2011.

ALMEIDA, A. W. B. Terras de quilombos, terras indígenas, "babaçuais livres", "castanhais do povo", faxinais e fundos de pasto: terras tradicionalmente ocupadas. 2. ed. Manaus: PPGSCA-UFAM, 2006.

ALVES DA SILVA, M. E. P. Pescadores e pescarias de pequena escala em comunidades Locais: o caso do Reservatório Billings (Alto Tietê, SP). 2008. 100f. Dissertação (Mestrado em Aquicultura e Pesca) - Instituto de Pesca/APTA/SAA-SP, São Paulo, 2008.

AMADO, C. M. M. História da pedagogia e da educação: guião para acompanhamento das aulas. 2007. Disponível em: <http://home.dpe.uevora.pt/ casimiro/HPE-\%20 Guiao\%20-\%20tudo.pdf>. Acesso em: 25 fev. 2017.

BORGES, I. B.; LIMA, R. B; FREITAS, R. R. Identificação e análise das vulnerabilidades socioeconômicas em comunidades pesqueiras localizadas em São Mateus, Espírito Santo, Brasil. In: CONGRESSO BRASILEIRO DE ENGENHARIA DE PRODUÇÃO, 6. Ponta Grossa, 2016. Anais... Paraná: Associação Paranaense de Engenharia de Produção, 2016. p. 11. BRANCO, J. O. et al. Aspectos sócio-econômicos da pesca artesanal do camarão sete-barbas (Xiphopenaeuskroyeri), na região de Penha, SC. Brazilian Journal of Aquatic Science and Technology, v. 11, n. 2, p. 25-32, 2007. 
BRASIL. Decreto n 10.408, de 7 de fevereiro de 2007. Institui a Política Nacional de Desenvolvimento Sustentável dos Povos e Comunidades Tradicionais. Diário Oficial da União, Brasília, 8 fev. 2007. Seção 1, p. 316. Disponível em: <http://www.planalto. gov.br/ccivil_03/_ato20072010/2007/decreto/d6040.htm>. Acesso em: 23 fev. 2017.

CARDOSO, L. F. C. E. Criança na pesca: brincadeira ou trabalho. In: SEMINÁRIO DE INICIAÇÃO CIENTÍFICA, 5. Belém, 1997. Anais... Belém: Museu Paraense Emilio Goeldi, 1997.

FILHO, A. C. Oprocesso de construção dos povose comunidades tradicionais no Brasil.2015.Disponívelem:<https:/www.kooperation-brasilien.org/de/themen/menschenrechte-gesellschaft/ traditionelle-voelker-gemeinschaften/o-processo-de-construcao-dos-povos-e-comunidades-tradicionais-no-brasil?set_language=pt-br>. Acesso em: 8 fev. 2017.

FREITAS, C. O. Gestão participativa da Colônia de Pescadores sob modelo PESTEL: de Pimenteiras D’Oeste/Rondônia. 1. ed. Letônia, União Europeia: Novas Edições Acadêmicas-NEA, 2015. v. 1, 156p.

GARCIA, N. M. Educação nas famílias de pescadores artesanais: transmissão geracional e processos de resiliência. 2007. 86f. Dissertação (Mestrado em Educação Ambiental) - Curso de Pós-Graduação em Educação Ambiental, Fundação Universidade Federal do Rio Grande, Rio Grande, 2007.

GOMES, R.K.S. et. al. Dinâmica socioambiental em uma comunidade pesqueira amazônica, PA-Brasil. Revista de Gestão Costeira Integrada, v. 9, n. 2, p. 101-111, 2009.

GROPPO, L. A.; GOUSSAIN, E. Dimensões educativas não formais e informais das práticas culturais juvenis na cidade. Revista Inter-ação, Goiânia, v. 41, n. 2, p. 265-286, maio/ago. 2016.

ITURRA,R. O processo educativo: ensino ou aprendizagem. 1994. Disponível em: <http://www.fpce.up.pt/ciie/revistaesc/ESC1/Iturra.pdf>. Acesso em: 3 mar. 2017.

JOSSO, M. C. A transformação de si a partir da narração de histórias de vida. Revista Educação, Porto Alegre, v. 30, n. 3, p. 413-438, set./dez. 2007. Disponível em: <http:// revistaseletronicas.pucrs.br/ojs/index.php/faced/article/view/2741/2088>. Acesso em: 3 mar. 2017.

LIMA, A. C. C.; CALLOU, A. B. F. Políticas públicas e assistência técnica para pesca artesanal em Pernambuco. Revista Contexto e Educação, v. 30, n. 95, p. 93-116, 2015.

MORAES, S.C.; LOPES, A.O. Saberes tradicionais e o uso de plantas medicinais em comunidade agrícola na Amazônia. In: ENCONTRO NACIONAL DE PESQUISA EM EDUCAÇÃO DO CAMPO, 2. Brasília, 2008. Anais... Brasília: EDUNB, 2008. p.34-36.

MINISTÉRIO DA PESCA E AQUICULTURA (MPA). Programa oferece 20 mil vagas para cursos de pesca e aquicultura. 2015. Disponível em: $<$ http://www.brasil.gov.br/educacao/2014/09/programa-oferece-20-mil-vagas-para-cursos-de-pesca-e-aquicultura $>$. Acesso em: 18 fev. 2017. 
PACHECO, M. J. Hidronegócio atinge a pesca artesanal: Movimento Nacional de Pescadores. Revista Instituto Humanistas Unisinos, Porto Alegre, 16 ago. 2012. (Entrevista concedida ao Instituto Humanitas Unisinos - IHU).

PAIOLA, L. M.; TOMANIK, E. A. Populações tradicionais, representações sociais e preservação ambiental: um estudo sobre as perspectivas de continuidade da pesca artesanal em uma região ribeirinha do rio Paraná. Revista Acta Scientiarum, Maringá, v.24, n.1, p.175-180, 2002.

PEDROSA, R. A. Pesca, perfil socioeconômico e percepção ecológica dos pescadores artesanais de Porto de Galinhas - PE. 2007. 87f. Dissertação (Mestrado em Oceanografia) - Curso de Pós-Graduação em Oceanografia, Universidade Federal de Pernambuco, Recife, 2007.

REIGOTA, M. Meio Ambiente e representação social. 2 ed. São Paulo: Ed. Cortez, 1994. (Questões da nossa época).

RODRIGO, M. J.; PALACIOS, J. Familia y desarrollo humano. Madrid: Alianza Editoria. 2014.

SCHRAM, S. C.; CARVALHO M. A. B. O pensar educação em Paulo Freire para uma pedagogia de mudanças. 2007. Disponível em:<http://www.diaadiaeducacao.pr.gov. br/portals/pde/arquivos/852-2.pdf >. Acesso em: 10 mar. 2017.

TÂNIA Olinda Lima: Possui graduação em Engenharia de Pesca pela Universidade Federal de Rondônia (2014), campus de Presidente Médici - Rondônia, Brasil. Pós-graduação lato sensu em Gestão Ambiental e Desenvolvimento Sustentável, em andamento mestrado pelo Programa de Pós-Graduação Mestrado e Doutorado em Geografia - PPGG, pela Universidade Federal de Rondônia (UNIR), campus de Porto Velho - Rondônia, na área de concentração: Ambiente e Território na Pan-Amazônia, linha de pesquisa: Paisagem, Processos do Meio Físico e Gestão Ambiental - PMG. Tem experiência na área de extensão rural; metodologias participativas; medicamento anestésico (Eugenol) para tambaqui (Colossomamacropomum); chipagem e biometria de peixes nativos da Amazônia, com ênfase em projetos agroecológicos voltados para o desenvolvimento local, tendo como foco pescadores artesanais, piscicultores e agricultura familiar.

E-mail: tania.enspesca@smail.com 
Ana Paula da Silva Bertão: Possui graduação em Engenharia de Pesca pela Universidade Federal de Rondônia (2014). Tem experiência na área de extensão rural; metodologias participativas; chipagem, biometria e manejo reprodutivo de peixes nativos da Amazônia, com ênfase em projetos voltados para o desenvolvimento local, sustentável e tecnológico, tendo como foco pescadores artesanais, agricultura familiar, gestão de propriedades rurais no âmbito de áreas da reforma agrária, piscicultores familiares e peixes amazônicos. Tem ainda experiência em projetos de pesquisa agroecológica familiar e artesanal, com $\circ$ intuito de fomentar a formação agroecológica e cidadã e fortalecer a inclusão social e produtiva de jovens agricultores e agricultoras familiares, visando à intensificação da participação social, da organização produtiva e do acesso a mercados, para a conquista de autonomia e afirmação do protagonismo juvenil, da valorização do espaço rural e do fortalecimento da agricultura familiar, por meio da consolidação de políticas públicas necessárias à permanência do jovem no território e à promoção do desenvolvimento sustentável rural em Rondônia. Tem também pós-graduação lato sensu em Gestão Ambiental e Desenvolvimento Sustentável.

E-mail: anabertaopaula@smail.com

Eliane Silva Leite: Possui graduação em Licenciatura em Física pela Universidade Federal de Rondônia (2006), mestrado (2009) e doutorado (2013) na área de Física Experimental pela Universidade de Brasília $\left(U_{n} B\right)$. Atualmente é professora adjunta do Departamento de Engenharia de Pesca da Universidade Federal de Rondônia e professora colaboradora do Mestrado Nacional Profissional em Ensino de Física, Polo do Departamento de Física da Universidade Federal de Rondônia. Áreas de atuação: educação, ensino de física e suas interdisciplinaridades, agroecologia, extensão rural, tecnologias socioambientais, pesca artesanal.

E-mail: esilva2308@gmail.com

Clodoaldo de Oliveira Freitas: Doutor em Administração pela Universidade Nacional de Misiones - UNAM - Argentina (2015), validado pela UFRJ (2016). Mestre em Administração pela Faculdade de Estudos Administrativos - FEAD/MG (2012) e graduado em Ciências Contábeis pela Universidade Federal de Rondônia (Cacoal, 2006), com licenciatura plena em Matemática pela Universidade Federal de Rondônia (Ji-Paraná, 1997), além de especialista em Matemática. Atualmente é professor adjunto da Universidade Federal de Rondô- 
nia - UNIR, dos Departamentos: de Engenharia de Pesca e Zootecnia do Campus de Presidente Médici - RO. Trabalha com administração rural, economia rural, cálculo, gestão de custos e gestão participativa. Desenvolve projetos de pesquisa e extensão com agroecologia, agricultura familiar, territorialidades e gestão de propriedades. Membro do Grupo de Estudo e Pesquisa em Biociências - GPBio.

E-mail: clodoaldo@unir.br 